OPEN ACCESS

Edited by:

Ernestina Marianna De Francesco,

University of Catania, Italy

Reviewed by:

Ana Paola Giometti Lombardi, Arctic University of Norway, Norway

Rosamaria Lappano,

University of Calabria, Italy

*Correspondence:

Erick Sierra-Diaz

erksland@hotmail.com

${ }^{+}$These authors have contributed equally to this work and

share fist authorship

Specialty section: This article was submitted to Molecular and Structural Endocrinology, a section of the journal

Frontiers in Endocrinology

Received: 18 November 2021

Accepted: 15 December 2021

Published: 11 January 2022

Citation:

Ramirez-de-Arellano $A$ Pereira-Suárez AL, Rico-Fuentes $C$, López-Pulido El, Villegas-Pineda JC and Sierra-Diaz E (2022) Distribution and Effects of Estrogen Receptors in

Prostate Cancer: Associated

Molecular Mechanisms.

Front. Endocrinol. 12:811578. doi: 10.3389/fendo.2021.811578

\section{Distribution and Effects of Estrogen Receptors in Prostate Cancer: Associated Molecular Mechanisms}

\author{
Adrián Ramírez-de-Arellano ${ }^{1 \dagger}$, Ana Laura Pereira-Suárez ${ }^{1,2 \dagger}$, Cecilia Rico-Fuentes ${ }^{3}$, \\ Edgar Iván López-Pulido ${ }^{3}$, Julio César Villegas-Pineda ${ }^{2}$ and Erick Sierra-Diaz ${ }^{4,5 *}$ \\ 1 Instituto de Investigación en Ciencias Biomédicas, Centro Universitario de Ciencias de la Salud, Universidad de \\ Guadalajara, Guadalajara, Mexico, ${ }^{2}$ Departamento de Microbiología y Patología, Centro Universitario de Ciencias de la \\ Salud, Universidad de Guadalajara, Guadalajara, Mexico, ${ }^{3}$ Centro Universitario de los Altos, Universidad de Guadalajara, \\ Tepatitlán de Morelos, Mexico, ${ }^{4}$ Departamentos de Clínicas Quirúrgicas y Salud Pública, Centro Universitario de Ciencias de \\ la Salud, Universidad de Guadalajara, Guadalajara, Mexico, ${ }^{5}$ Departamento de Urología, Hospital de Especialidades Centro \\ Médico Nacional de Occidente, Guadalajara, Mexico
}

Estrogens are hormones that have been extensively presented in many types of cancer such as breast, uterus, colorectal, prostate, and others, due to dynamically integrated signaling cascades that coordinate cellular growth, differentiation, and death which can be potentially new therapeutic targets. Despite the historical use of estrogens in the pathogenesis of prostate cancer (PCa), their biological effect is not well known, nor their role in carcinogenesis or the mechanisms used to carry their therapeutic effects of neoplastic in prostate transformation. The expression and regulation of the estrogen receptors (ERs) ER $\alpha$, ER $\beta$, and GPER stimulated by agonists and antagonists, and related to prostate cancer cells are herein reviewed. Subsequently, the structures of the ERs and their splice variants, the binding of ligands to ERs, and the effect on PCa are provided. Finally, we also assessed the contribution of molecular simulation which can help us to search and predict potential estrogenic activities.

Keywords: prostate cancer, estrogen receptor, castration - resistant prostate cancer, androgen deprivation therapies, GPER

\section{INTRODUCTION}

Prostate cancer (PCa), is the second leading cancer-related disease among men and the fifth leading cause of death worldwide (1). This disease at the early stage can often be cured, however, those patients with metastasis need to undergo androgen deprivation therapy (ADT) (2), which progresses into a drug resistance stage, termed castration-resistant prostate cancer (CRPC). Although studies with an androgen receptor (AR) suggest that before ligand binding the receptor is located in the cytoplasm, that may in fact be a nucleus like downregulation of ER $\beta$ mRNA expression in hormone-refractory tumors, which provokes the acquisition of mesenchymal characteristics and aggressive behavior of the PCa cells (3) which could influence clinical symptomatic cancer and the initiation of PCa. Moreover, before nuclear translocation, ligandbound steroid hormone receptors, both AR and ER can bind to homologous or heterologous ligands in the cytoplasm and exert biological effects (4). 
ERs are activated by steroid hormones, such as estrogens, and mediate important physiological effects by binding to ERs (5). A specific ligand can exert an agonistic effect with an affinity depending upon the ER, implicated in non-receptor tyrosine kinase (Src) activation and phosphoinositol 3-kinase (PI3K) signaling pathway (6).

Therefore, it is important to improve this information so it can develop into potential tools for further investigation.

\section{STRUCTURAL DIVERSITY OF ESTROGEN RECEPTORS}

$\mathrm{ER} \alpha$ and $\mathrm{ER} \beta$ are nuclear ERs, although both receptors interact with $17 \beta$ - estradiol with high affinity, with the difference being in respect of the level of induction that may relate to the ligand (coactivation/repressors) (7). These receptors bind to specific sequences in gene promoters or through mechanisms that do not involve DNA binding (genomic and non-genomic effects) (8).

ERs are comprised of various domains and have several structural regions in common. The main functional domains are termed $\mathrm{A} / \mathrm{B}, \mathrm{C}, \mathrm{D}$, and $\mathrm{E} / \mathrm{F}$ are present in both receptors' fulllength structures (4). The A/B region represents the aminoterminal domain (NTD) which is involved in transcriptional transactivation of gene. The $\mathrm{C}$ region corresponds to the DNA binding domain (DBD), contributing to the estrogen receptor dimerization. The $\mathrm{D}$ domain is a hinge region that connects the $\mathrm{C}$ and $\mathrm{E}$ domains, and it can bind to chaperone proteins allowing for the receptor-ligand complexes to translocate to the nucleus. The carboxy-terminal E/F region, also known as the ligandbinding domain (LBD), contains the estrogen binding area and binding sites for co-activators and co-repressors. Lastly, two additional regulators of estrogen activity, known as activation function (AF) domains, AF1 and AF2, are located within the NTD and DBD. The function of the former is hormone independent (AF1), and the latter requires the presence of hormone/steroid for transcriptional activation (AF2) (9).

$\mathrm{ER} \alpha$ and $\mathrm{ER} \beta$ are isoforms of ER, which show high homology (more than 95\% amino acid identity in the DBD domains and about 55\% amino acid identity in the LBD) (4). (Figure 1, I).

The LBD is responsible for most of the functions activated by ligand binding, such as coregulator binding to AF2 (10) and dimerization interface, while DBD in ERs usually binds with high affinity to EREs and transactivates the gene expression in response to estrogen. The EREs sequencing performs an important regulatory role by dictating the binding affinity of ERs and modulating the recruitment of co-activators (4) (Figure 1, II).

Two mechanisms of action of the ligand-ER mediating the transcriptional regulation at ERE are reported. The binding of the ligand to the receptor triggers a variety of coregulators in a complex that alters chromatin and facilitates the transcriptional machinery. In this way, the Estrogen-ER complex acts as a

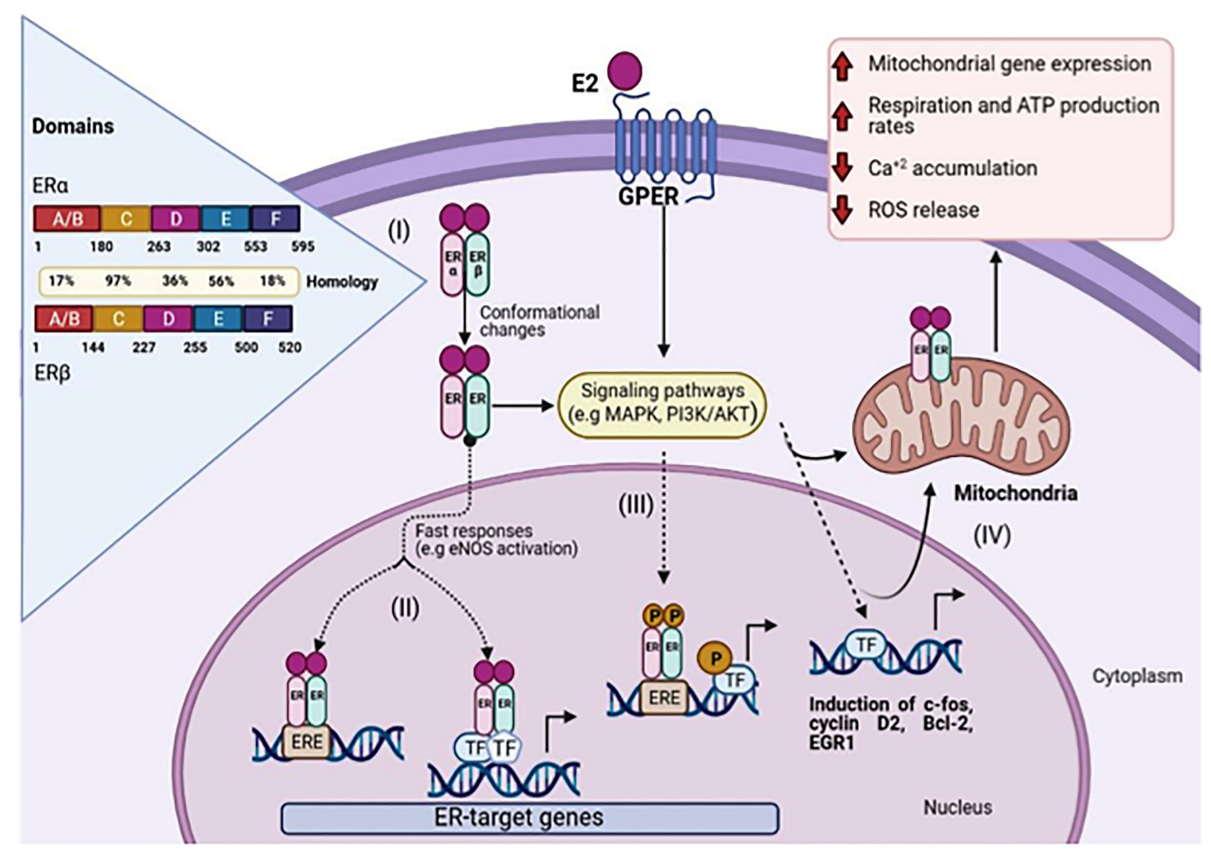

FIGURE 1 | Schematic representation of $17 \beta$-Estradiol induced estrogen receptor- $\alpha$, $\beta$, and GPER signaling. (I) The amino acid sequence position is shown for each domain and the homology between ER $\alpha$ and ER $\beta$. Genomic pathway: (II) The E2/ER complex can bind to estrogen response elements (ERE) within the target gene promoter or regulate gene transcription by interacting with other transcription factors (TF), e.g. AP-1 and Sp1. (III) In addition, E2/ER complex activates signaling transduction pathways, leading to phosphorylation of ER or other bound transcription factors modulating gene expression. (IV) E2 initiated cellular and mitochondrial ER/GPER genomic and non-genomic actions modulate mitochondrial respiration, ATP production, and ROS formation. (Figure created with BioRender.com). 
transcriptional activator promoting gene expression (11), and another mechanism is by indirect genomic signaling of $17 \beta$ estradiol, through protein-protein interactions with other classes of transcription factors at their respective response elements (12).

GPER is an estrogen receptor that was identified some decades ago. It belongs to the GPCR family (13). Unlike other family members, the GPER binding domain is present inside the plasma membranes (14) and the endoplasmic reticulum (15). After ligand binding to GPER, the activation stimulates cAMP production, calcium mobilization, and $c$-Src, which activates MMPs. It has also been demonstrated that these MMPs transactivate EGFR, which in turn activates MAPK and PI3K/ AKT pathways that can induce non or genomic effects (16). (Figure 1, III), which causes diverse biological effects on the regulation of cell growth, migration, and programmed cell death in various tissues including the nervous, reproductive, digestive, and muscle systems (17).

GPER regulation of cell proliferation and apoptosis has also been linked with processes, namely, oxidative stress and $\mathrm{Ca}^{+2}$ homeostasis (Figure 1, IV). In the scenario of cell-fate maintenance of tissue homeostasis, the dual effects of GPER in the control of cell proliferation and apoptosis became evident, and consequently, depends on a panoply of factors that may include the type of tissue and a physiological context (18).

\section{SPLICE VARIANTS IN THE ESTROGEN RECEPTOR}

Different ER variants have been reported. Recently, Qu et al. characterized circulating estrogen receptor mutants and isoforms in men from blood-derived RNA samples that were sequentially characterized from healthy and advanced PCa patients. The authors found six ER $\alpha$ mutations (E380Q, L536Q, Y537C, Y537S, Y537N, and D538G) in plasma from patients with advanced $\mathrm{PCa}$, and six ER $\alpha$ and $\mathrm{ER} \beta$ isoforms (ER $\alpha-66, \mathrm{ER} \alpha-$ 36, ER $\beta 1, \mathrm{ER} \beta 2, \mathrm{ER} \beta 4$, and $\mathrm{ER} \beta 5$ ) (19).

A novel splice variant of the human ER $\alpha, E R \alpha 30$, was recently identified and cloned from clinical breast cancer tissue (20). The ER $\alpha-30$ sequence lacks an LBD and a liganddependent transcriptional activation domain but retains the $\mathrm{N}$ terminal transcriptional activation domain, the DBD, a partial hinge domain and possesses a unique 10-aminoacid domain. Nonetheless, different isoforms are generated not only by alternative splicing but also through post-transcriptional modifications (20).

The $\mathrm{ER} \alpha-36$ is a $36-\mathrm{kDa}$ novel isoform of $\mathrm{ER} \alpha$ that was identified and cloned by Wang et al. It is considered a new and important factor in understanding the pleiotropic effects of estrogen, even in organs without ER $\alpha-66$ (21). Comparing human ER $\alpha-36$ and ER $\alpha-66$, the aforementioned lacks both transcriptional activation domains (AF-1 and AF-2) but retains the DBD and partial dimerization and the LBD, as in ER $\alpha-66$ (22). Therefore, ER $\alpha 36$ expression is lower in tissues known to be predominantly regulated through ER $\alpha 66$ by the influence of non-genomic signaling (23).

ER $\beta$ may play a significant role in PCa affecting progression by expressing spliced variants. It has a full-length helix 11 and a helix 12 that assumes an agonist-directed position. In ER $\beta 2$, the C-terminus results in a disoriented helix 12 and it is marked in the coactivator binding cleft. ER $\beta 4$ and ER $\beta 5$ completely lack helix 12. Thus, ER $\beta$ behaves like a non-canonical type-I receptor. Its action may depend on differential amounts of ER $\beta 1$ homo and heterodimers formed upon stimulation by a specific ligand. Leung et al. suggest that all heterodimers have a higher transactivation activity than the ER $\beta 1$ homodimer, which serves as the "obligatory partner" of a functional dimeric complex, whereas ER $\beta 2$, ER $\beta 4$, and ER $\beta 5$ act as the "variable dimer partners" and serve as enhancers (24).

The cross-reactivity between different estrogenic ligand with $\mathrm{ER} \alpha$ and ER $\beta$ isoforms in specific cellular contexts, and the fact that these receptors can recognize the same DNA-binding sites and interact with common co-regulators, seems to be a challenge, especially for those targeting hormone signaling pathways. In contrast, the splice variants are likely to be derived from nonmalignant and malignant cells, especially as all six ER splice variants were detected in both healthy and ill patients (25), highlighting the importance of further research.

\section{DISTRIBUTION OF ESTROGEN RECEPTORS AND EFFECTS ON PROSTATE CANCER}

The function of ERs depends upon their concentration and the presence of potential coregulatory proteins to ultimately repress or activate the expression of target genes (26).

$\mathrm{ER} \alpha$ and $\mathrm{ER} \beta$ have specific roles in PCa. It is known that ER $\alpha$ promotes proliferation, inflammation, and migration, whereas ER $\beta$ is considered antiproliferative and tumor-suppressive, and the loss of it has been associated with the progression to castration resistance (27) However, it has been considered that activation of ER $\beta$ increase non-phosphorylated $\beta$-catenin which promotes migration and invasion therefore it is currently consider as a controversy.

$\mathrm{ER} \alpha 36$ is localized in the membrane and contains the DNAbinding and dimerization domains from ER $\alpha$ by lacking both transcriptional activation domains (28), It is reported that high $\mathrm{ER} \alpha \mathrm{mRNA}$ and protein levels were detected in hormonerefractory and metastatic lesions with lymph node and bone metastatic samples (3). However, the exact role of $\mathrm{ER} \alpha$ in prostate tumorigenesis is through MAPK/ERK, PI3K/AKT and $\beta$-catenin pathways, however the formation of metastatic lesions has not been investigated enough.

In benign prostate glands, ER $\beta 1$ was localized principally in the cytoplasm and nucleus of basal epithelial cells, but was also found in the perinuclear zone in luminal epithelial cells. Conversely, ER $\beta 2$ was localized predominantly in the cytoplasm of both basal and luminal epithelial cells. However, 
ER $\beta 5$ was localized almost exclusively in basal epithelial cells (27). The isoforms of $\operatorname{ER} \beta$ in aggressive prostate increase cell migration and cell invasiveness. These findings established that ER $\beta 2$ and ER $\beta 5$ are strongly associated with PCa metastasis (29).

A recent study showed that the ER $\beta 2$ splice variant had oncogenic properties and was involved in osteolytic bone metastasis, in strong contrast to the tumor-suppressing effects of the other isoform ER $\beta 1$ (30). ER $\beta$ expression is located in dysplasia and was found to be associated with poor relapse-free survivals, when is located in cytoplasm and promotes aggressive behaviors of the cells with high-grade PCa $(24,31,32)$.

A strong correlation between GPER and progression in the male reproductive system has been reported, which regulates testosterone and estrogen balance. Lower GPER expression was detected in benign prostatic tissues, and was mainly located in the epithelial basal layer, where this receptor could mediate estrogen action on normal cellular activity, and in neoplastic prostatic cells (33),. Therefore, benign prostate epithelial cells were noted to possess strong GPER immunoreactivity, indicating that expression of this receptor is inversely correlated to the degree of neoplastic cell differentiation (34). However, Chan et al. suggested GPER as a tumor suppressor by sustained activation of ERK1/2 and c-Jun/c-Fos-dependent, resulting in the arrest of PC3 growth at the G2 phase (35).

\section{ER-LIGAND ASSAYS RELATED TO PROSTATE CANCER}

$\mathrm{ER} \alpha, \mathrm{ER} \beta$, and GPER mediate the effects of estrogens in the normal prostate gland, a membrane-bound receptor, that is responsible for the rapid genomic and non-genomic actions of estrogens, which activate various protein-kinase cascades. During the progression of PCa, dynamic changes in both ER $\alpha$ and ER $\beta$ expression have been observed, which show a significant reduction of these receptors in tumor-associated stroma, compared to those of adjacent benign prostate. Additionally, ER $\alpha$ levels were higher in a higher-grade cancer compared to those at an early stage (36).

Conversely, the activation of ER $\beta$ induces anti-tumoral activity in PCa cells by repressing key oncogenes (PI3K, p45Skp2, c-Myc, and cyclin E, and the oncogenic TMPRSS2$E R G$ fusion), by increasing the expression of antiproliferative genes (PTEN, FOXO3, KLF5, p21WAF1, CDKN1A, and p27Kip1) as well as E-cadherin (37). Furthermore, ER $\beta$ signaling could be protective at an early stage of prostate carcinogenesis and it is shown that can switch during progression promoting migration, invasion and proliferation (38).

Interestingly, authors found the effect of agonist in ER which can modulate signaling pathways, such as ER $\alpha$-selective agonist tri phenol (PPT) and ER $\beta$-selective agonist diarypropionitrile (DPN) induce an increase on ERK1/2 but not AKT in the extranuclear region which would be important in order to develop new therapeutic strategies for the CRPC (39).

\section{GPER LIGANDS IN PROSTATE CANCER}

Chan et al. have previously reported that the stimulation of GPER by G-1, which is a specific agonist of GPER with no function on $\mathrm{ER} \alpha$ and $\mathrm{ER} \beta$, impedes prostate cancer cell growth in vitro and in vivo assays (35). In a recently related study, Lau et al. reported that the binding of G-1 to GPER stimulates Gail proteins that sustains ERK1/2 activation but fails to activate adenylyl cyclase (AC) for cAMP production (40). Gail is expressed during $\mathrm{PCa}$, and silences these proteins that inhibit cell growth of G-1. Furthermore, the stimulation of GPER by G-1 hampers the migration and invasion of PCa cells.

Chan et al. reported that activation of GPER with G-1 inhibits the growth of androgen-dependent and androgen-independent PCa cells in vitro and PC-3 xenografts in vivo, through sustained activation of ERK1/2, c-Jun/c-Fos-dependent up-regulation of cyclin-dependent kinase inhibitor 1 (p21), and induction of G2 cell-cycle arrest (35).

However, other signaling pathways resulted from the stimulation of GPER with other ligands have not yet been fully elucidated. In another research paper, they found, the relation between G-1 and androgen expression may impact G-1 in vivo studies, and as such, is yet to be made clear. Concerning LNCaP cell xenograft, the authors reported that during the androgensensitive (AS) versus castration-resistant (CR) phase, G-1 inhibited the growth of CR, contrarily to the AS tumors, and no toxicity of the host was noticed (41).

This inhibiting effect was associated with massive necrosis, neutrophil infiltration, up-regulation of a set of cell-mediated immune-response genes, and enhanced expression of GPER. The cell-based experiments revealed that GPER is repressed by androgen, whereas immunohistochemical studies, which found a larger proportion of human CRPC metastases than primary PCa, express high GPER levels (41).

Their results provided the first evidence that the GPER is an androgen-repressed target, and G-1 mediates the antitumor effect via neutrophil infiltration-associated necrosis in CRPC. Conversely, the lack of acetyl group in G-15 compared to G-1 prevents biological responses mediated by GPER in cancer cells and in vivo like epithelial uterine cell proliferation and antidepressive effects in mice, contrarily to G-1 and estrogens. In the previous reference, the authors suggest that the antagonist of GPER may display similar selectivity against uterine and neurological responses initiated by estrogen.

\section{ASSOCIATED MECHANISMS BETWEEN ER AND GPER IN PROSTATE CANCER}

Estrogens are critical hormones that regulate the development of hormone-sensitive tumors. It is known that any compound that up-regulates aromatase levels will not only elevate intracellular E2, but will also increase the activation of the mainly proliferative, classic ER $\alpha$ to induce adipogenesis and growth 
disorders in estrogen-sensitive tissues, as well as GPER that alters important intracellular signaling sequences that promote mitogenic growth and endothelial damage (42). Unfortunately, the physical effects of illness and inflammation activate aberrant signal transduction and anti-apoptotic processes by altering serine/threonine phosphorylation cascades of multiple tyrosine kinase receptors that act through MEKK/ERK and PI3K/Akt/ mTOR/NF-kB pathways (43) (Figure 2).

Therefore, differentiating functions of splice variants for estrogen receptors will further clarify our understanding of their roles in PCa progression. While the role of ER $\beta$ in PCa is well studied, there are relatively few studies on the functional role of ER $\alpha$ in prostate tumorigenesis (44).

Through ER $\alpha-36$ that induces the initiation of non-genomic signaling pathways to activate MAPK/ERK and PI3K/AKT pathways, this regulates $\mathrm{c}-\mathrm{Myc}$ protein expression, thereby contributing to the metastatic potential of cancer. The interaction of ER $\alpha-36$ with E2 causes Src activation inducing downstream cascades: MEK activation, phosphorylation of ERK and paxillin $(\mathrm{PXN})$, which induces third messenger expression, cyclin D1 (45) and protein kinase C (PKC) through ERK1/2 leading to an increase in cyclin D1/cyclin-dependent kinase 4 which control cell cycle progression, proliferation, metastasis, and survival (46)

Moreover, several studies suggest that ER $\alpha-36$ could act as a negative dominant regulator of estrogen genomic signaling promoted by ER $\alpha-66$ and ER $\beta$. However, there is a positive feedback mechanism between ER $\alpha-66$ and ER $\alpha-36$. ER $\alpha-66$ appears to be able to suppress ER $\alpha-36$ activity, and the loss of ER $\alpha-66$ expression increases $\operatorname{ER} \alpha-36$, which represents one of the resistance mechanisms to antiestrogen therapy (46). To our knowledge, the signaling related to $\mathrm{ER} \alpha-66$ in PCa needs to be researched.

$\mathrm{ER} \beta$ isoforms in $\mathrm{PCa}$ are known to down-regulate the progression of this disease and the expression of androgens receptors (AR) (47), as seen in ER $\beta 1$, whose depletion increases AR. In addition, ER $\beta 1$ has been shown to induce apoptosis in PCa cell lines by activating the FOXO3 and PUMA pathway (36) and inhibit EMT by upregulating prolyl hydroxylase domain 2 (PHD2/ EGLN1), and subsequently decreasing hypoxia levels (24). Alternatively, ER $\beta 2$ is expressed in metastatic prostate cancer and its location in the nucleus correlates with decreased survival (29), increased invasiveness, cell proliferation, expression of Twist 1 and $c-M y c$ in PC3 and 22Rv1 cells, thus indicating possible oncogenic roles of ER $\beta 2$ in PCa (30).

It is shown that ER $\beta 2$ interacts and stabilizes HIF- $1 \alpha$ protein in normoxia by inducing a hypoxic gene expression signature. HIF- $1 \alpha$ stimulates metastasis by increasing Twist 1 expression and increasing vascularization by activating VEGF expression (48). These findings suggest that ER $\beta 2$ is mediated by HIF- $1 \alpha$, and these interactions may be a strategy for treating PCa.

The increased activity of $\operatorname{ER} \alpha$ and $\operatorname{ER} \beta$ can alter the homeostatic balance of the GPER transmembrane regulatory cascade, and in turn, these pathways increase growth, stimulate anti-apoptotic processes, activate mitogenic change, and metaplastic alteration, and well as neoplastic activity in estrogen-sensitive tissues (6).

For instance, an interesting co-dependence between GPER and $E R \alpha$ toward the stimulation of gene expression and cell proliferation has been revealed, and it includes the up-regulation of c-Fos, CTGF,Egr1 (17) and other genes involved in important biological responses.

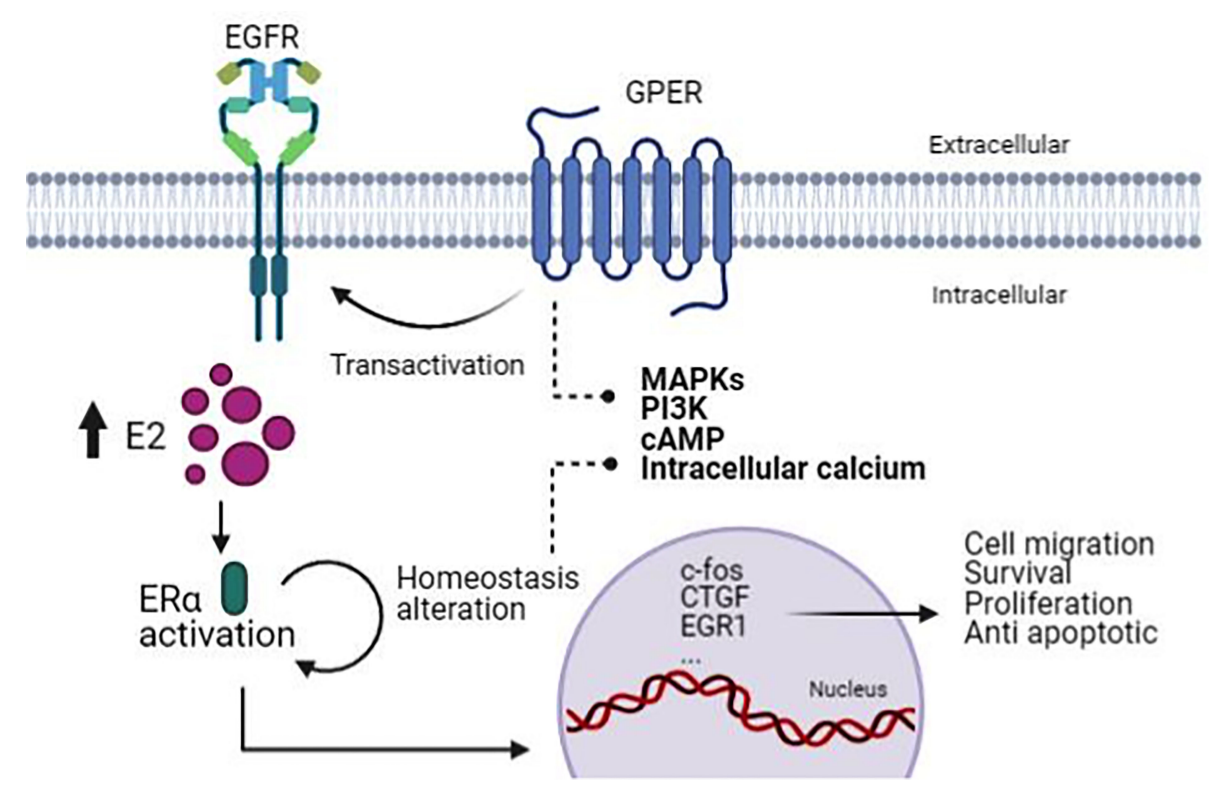

FIGURE 2 | The mechanism associated with ER and GPER in PCa. Due to the increasing activity of ER $\alpha$, this brings about homeostasis alteration that GPER transactivates EGFR, causing activation of pathways involved in cell migration, survival, proliferation, and anti-apoptotic process. (Figure created with BioRender.com). 


\section{MOLECULAR SIMULATIONS OF ESTROGEN RECEPTORS}

Molecular simulation is a handy and powerful tool. Nowadays, theoretical calculations on this topic can provide some insights into the binding of a ligand to a receptor and help develop novel specific drugs, which is currently one of the greatest challenges of the pharmaceutical industry. The binding of a ligand to the ERs occurs in the LBD, which presents a canonical antiparallel ahelical triple sandwich topology, similar to other NRs. The interactions of ER $\alpha$ and ER $\beta$ with ligands are commonly the targets in molecular simulation.

Lin et al. explores a prostate-associated gene, an intrinsically disordered protein implicated in PCa. They performed molecular dynamics simulations to understand the interactions underlying this structural transition, which show that electrostatic interaction drives the transient formation of an $\mathrm{N}$-terminal loop, that causes a dramatic change in size upon hyperphosphorylation. This leads to constructing a mechanism-based mathematical model that allows capturing the interaction of different phosphorylated forms of PAGE4 with AP-1 and its downstream target, the androgen receptor, a key therapeutic target in PCa (49). Their model predicts intracellular oscillatory dynamics indicating phenotypic heterogeneity in an isogenic cell population, in order to gain insights into its functional implication that may modulate hormone expression in PCa cell though future therapy interactions.

\section{ESTROGENS AND PROSTATE CANCER PATIENTS}

Prior to ADT, prostate cancer was managed using estrogen treatment. The secondary cardiovascular effects were a serious concern for therapy, since its use was limited to prostate cancer patients (50). Regarding the clinical field and novel research, a type of androgen-dependent tumor remains as a paradigm for PCa. Although the role of estrogen on PCa development is important, scientific information is scarce. The association between plasma estrogens remains unclear and sometimes contradictory, since circulating testosterone in plasma decreases with age. Increasing the ratio of estradiol testosterone leads to aromatase activity and higher conversion of testosterone to estradiol $(51,52)$. Malignant and nonmalignant prostate cells are provided with key enzymes of steroid metabolism (17ß-hydroxysteroid dehydrogenases, 5ßreductase, and aromatase). Metabolic activity of these compounds may in the end lead to a differential prostate accumulation of steroid by-products with no clear behavior (51).

Nowadays, the clinical field regarding PCa management is broader. Around 15 years ago, progression to androgen deprivation management in metastatic castration-resistant prostate cancer (mCRPC) cases, were managed based on hormonal manipulation with antiandrogens such as nilutamide and bicalutamide (53). New chemical compounds have been approved for high risk mCRPC, including enzalutamide and abiraterone, which are associated with longer disease control and survival if combined with androgen deprivation therapy (54). The targeted androgen receptor inhibitor enzalutamide blocks the androgen receptor binding to DNA, and androgen receptor translocation to the cell nucleus. Abiraterone is a selective inhibitor of CYP17. Its effect on CYP17 results in an increased level of mineralocorticoids, due to high levels of the adrenocorticotropic hormone (53). Inhibition of CYP17 blocks androgen synthesis by producing tumor responses in prostate cancer patients who no longer respond to standard hormonal therapies (55).

In 2021, Jurečeková et al. revived scientific focus on estrogen activity in $\mathrm{PCa}$, subject to the possibility that an intraprostatic estrogen milieu might have a role that is more important than only circulating estrogen levels. They determined the ESR2 expression levels in malignant prostate tissues and analyzed a possible association with ERS2 gene polymorphisms (52). The case control study, which included 510 prostate cancer patients, concluded that the polymorphism rs3020449 in the ESR2 gene should be considered as a risk factor for prostate cancer in Slovak males. This polymorphism was associated with high grade carcinomas (Gleason score $>7$ ) and stages pT3/pT4.

As previously mentioned, current cancer research is focused on androgen receptor signaling. Evidence of estrogen and estrogen receptors in prostate cancer pathology is not conclusive, nor are there any clear results, due to a lack of information. A new compound for prostate cancer treatment such as abiraterone acetate, which induces a wide effect on several hormones and its receptors, could be the first step towards estrogen receptors interest for future research.

\section{DISCUSSION}

The present review highlights the recent research advances in prostatic cancer and provides an overview for further research work related to this topic. It has been recognized for many years that ER is a predictor of hormone responsiveness. Furthermore, there is ER expression in positive cancer that does not respond and generate resistance, and unfortunately, the consequences of hormonal therapy is that many patients who do respond will eventually relapse in consequence of the development of resistance (3). This is unlikely to be due to major losses of Ero, since the immunohistochemical analysis of paired biopsies taken before tamoxifen treatment and following relapse showed a loss in only about $20 \%$ of the cases (56).

Alternatively, ER $\beta$ led investigators to hypothesize that this might be involved in phenotypic resistance, and was associated with poor prognosis and an elevated expression of ER $\beta$ (57). Also, the responses mediated by GPER have a critical interaction in PCa, since it plays an important role in tumor development and metastasis by activating signaling pathways involved in exacerbated proliferation, resistance to apoptosis, stimulated migration and invasion, induction of angiogenesis, and metabolic reprogramming (24).

The screening of various compounds by molecular simulation is beneficial to finding promising selective agonists or antagonists, and significantly contributes to successful drug design. 
It is widely known that estrogen is associated with carcinogenesis through specific mechanisms, and multiple variants of ER are involved in pathophysiology and signaling pathways in PCa. GPER is expressed both in the normal gland and PCa. Overall, a deeper knowledge of the roles of ER $\alpha$ or ER $\beta$ and their interaction with GPER is required in order to apply future therapies to PCa. Molecular simulations will aid in deciding which receptor subtype should best be targeted for the management or cure of this pathological disorder.

However, in vitro and in vivo bioassays are undoubtedly indispensable. It should be mentioned that the activity elicited by ER antagonists, though ER $\alpha$ and GPER as stated above, could represent a therapeutic concern with regard to the pharmacological manipulation of cancer cells, through inhibiting all types of estrogen receptors, however, in $\mathrm{PCa}$, it has not yet been fully elucidated

\section{REFERENCES}

1. Rawla P. Epidemiology of Prostate Cancer. World J Oncol (2019) 10(2):63-89. doi: 10.14740/wjon1191

2. James ND, Sydes MR, Clarke NW, Mason MD, Dearnaley DP, Spears MR, et al. Addition of Docetaxel, Zoledronic Acid, or Both to First-Line LongTerm Hormone Therapy in Prostate Cancer (STAMPEDE): Survival Results From an Adaptive, Multiarm, Multistage, Platform Randomised Controlled Trial. Lancet (2016) 387(10024):1163-77. doi: 10.1016/S0140-6736(15) 01037-5

3. Bonkhoff H. Estrogen Receptor Signaling in Prostate Cancer: Implications for Carcinogenesis and Tumor Progression. Prostate (2018) 78(1):2-10. doi: 10.1002/pros.23446

4. Yaşar P, Ayaz G, User SD, Güpür G, Muyan M. Molecular Mechanism of Estrogen-Estrogen Receptor Signaling. Reprod Med Biol (2016) 16(1):4-20. doi: $10.1002 / \mathrm{rmb} 2.12006$

5. Cleve A, Fritzemeier KH, Haendler B, Heinrich N, Möller C, Schwede W, et al. Pharmacology and Clinical Use of Sex Steroid Hormone Receptor Modulators. Handb Exp Pharmacol (2012) 214):543-87. doi: 10.1007/978-3642-30726-3_24

6. Zekas E, Prossnitz ER. Estrogen-Mediated Inactivation of FOXO3a by the G Protein-Coupled Estrogen Receptor GPER. BMC Cancer (2015) 15:702. doi: 10.1186/s12885-015-1699-6

7. Mosselman S, Polman J, Dijkema R. ER Beta: Identification and Characterization of a Novel Human Estrogen Receptor. FEBS Lett (1996) 392(1):49-53. doi: 10.1016/0014-5793(96)00782-x

8. Fuentes N, Silveyra P. Estrogen Receptor Signaling Mechanisms. Adv Protein Chem Struct Biol (2019) 116:135-70. doi: 10.1016/bs.apcsb.2019.01.001

9. Kundu P, Li M, Lu R, Stefani E, Toro L. Regulation of Transcriptional Activation Function of Rat Estrogen Receptor $\alpha$ (Er $\alpha$ ) by Novel C-Terminal Splice Inserts. Mol Cell Endocrinol (2015) 401:202-12. doi: 10.1016/j.mce.2014.11.001

10. Ahirwar R, Nahar S, Aggarwal S, Ramachandran S, Maiti S, Nahar P. In Silico Selection of an Aptamer to Estrogen Receptor Alpha Using Computational Docking Employing Estrogen Response Elements as Aptamer-Alike Molecules. Sci Rep (2016) 6:21285. doi: 10.1038/srep21285

11. Liu H, Yan Y, Wen H, Jiang X, Cao X, Zhang G, et al. A Novel Estrogen Receptor GPER Mediates Proliferation Induced by $17 \beta$-Estradiol and Selective GPER Agonist G-1 in Estrogen Receptor $\alpha$ (Er $\alpha$ )-Negative Ovarian Cancer Cells. Cell Biol Int (2014) 38(5):631-8. doi: 10.1002/cbin.10243

12. Vrtačnik P, Ostanek B, Mencej-Bedrač S, Marc J. The Many Faces of Estrogen Signaling. Biochem Med (Zagreb) (2014) 24(3):329-42. doi: 10.11613/ BM.2014.035

13. Thomas P, Pang Y, Filardo EJ, Dong J. Identity of an Estrogen Membrane Receptor Coupled to a G Protein in Human Breast Cancer Cells. Endocrinology (2005) 146(2):624-32. doi: 10.1210/en.2004-1064

14. Sjöström M, Hartman L, Grabau D, Fornander T, Malmström P, Nordenskjöld B, et al. Lack of G Protein-Coupled Estrogen Receptor

\section{AUTHOR CONTRIBUTIONS}

All authors participated directly in the manuscript. AR-d-A, AP-S, and ES: Conceptualization, project administration and writing-original draft preparation. ES: Editing. CR-F, EL-P, and JV-P: Investigation and writing-review. CR-F: Digital art $\left(\right.$ BioRender ${ }^{\circledR}$ ). All authors have read and agreed to the published version of the manuscript.

\section{FUNDING}

This work was supported by Jalisco Scientific Development Fund (FODECIJAL) to Attend State Problems 2019 (Project \#8164).
(GPER) in the Plasma Membrane Is Associated With Excellent Long-Term Prognosis in Breast Cancer. Breast Cancer Res Treat (2014) 145(1):61-71. doi: 10.1007/s10549-014-2936-4

15. Camilletti MA, Abeledo-Machado A, Ferraris J, Pérez PA, Faraoni EY, Pisera D, et al. Role of GPER in the Anterior Pituitary Gland Focusing on Lactotroph Function. J Endocrinol (2019) 240(2):99-110. doi: 10.1530/JOE-18-0402

16. Souza DS, Lombardi APG, Vicente CM, Lucas TFG, Erustes AG, Pereira GJS, et al. Estrogen Receptors Localization and Signaling Pathways in DU-145 Human Prostate Cancer Cells. Mol Cell Endocrinol (2019) 483:11-23. doi: 10.1016/j.mce.2018.12.015

17. Chen ZJ, Wei W, Jiang GM, Liu H, Wei WD, Yang X, et al. Activation of GPER Suppresses Epithelial Mesenchymal Transition of Triple Negative Breast Cancer Cells via NF-kb Signals. Mol Oncol (2016) 10(6):775-88. doi: 10.1016/j.molonc.2016.01.002

18. Kurt AH, Çelik A, Kelleci BM. Oxidative/Antioxidative Enzyme-Mediated Antiproliferative and Proapoptotic Effects of the GPER1 Agonist G-1 on Lung Cancer Cells. Oncol Lett (2015) 10(5):3177-82. doi: 10.3892/ol.2015.3711

19. Qu LG, Wardan H, Davis ID, Iddawela M, Sluka P, Pezaro CJ. Circulating Oestrogen Receptor Mutations and Splice Variants in Advanced Prostate Cancer. BJU Int (2019) 124 Suppl 1:50-6. doi: 10.1111/bju.14797

20. Desouza J, Gadkar S, Jagtap D, Sachdeva G. Size, Site, and Signaling: Three Attributes of Estrogen Receptors. BioMed Res J (2019) 6(2):37. doi: 10.4103/ BMRJ.BMRJ_24_19

21. Mahboobifard F, Dargahi L, Jorjani M, Ramezani Tehrani F, Pourgholami MH. The Role of Ero36 in Cell Type-Specific Functions of Estrogen and Cancer Development. Pharmacol Res (2021) 163:105307. doi: 10.1016/ j.phrs.2020.105307

22. Irsik DL, Carmines PK, Lane PH. Classical Estrogen Receptors and Ero Splice Variants in the Mouse. PloS One (2013) 8(8):e70926. doi: 10.1371/ journal.pone.0070926

23. Chakrabarti S, Davidge ST. G-Protein Coupled Receptor 30 (GPR30): A Novel Regulator of Endothelial Inflammation. PloS One (2012) 7(12):e52357. doi: 10.1371/journal.pone.0052357

24. Leung YK, Lam HM, Wu S, Song D, Levin L, Cheng L, et al. Estrogen Receptor Beta2 and Beta5 Are Associated With Poor Prognosis in Prostate Cancer, and Promote Cancer Cell Migration and Invasion. Endocr Relat Cancer (2010) 17 (3):675-89. doi: 10.1677/ERC-09-0294

25. Liu J, Sareddy GR, Zhou M, Viswanadhapalli S, Li X, Lai Z, et al. Differential Effects of Estrogen Receptor $\beta$ Isoforms on Glioblastoma Progression. Cancer Res (2018) 78(12):3176-89. doi: 10.1158/0008-5472.CAN-17-3470

26. Nelson AW, Tilley WD, Neal DE, Carroll JS. Estrogen Receptor Beta in Prostate Cancer: Friend or Foe? Endocr Relat Cancer (2014) 21(4):T219-34. doi: 10.1530/ERC-13-0508

27. Lombardi APG, Vicente CM, Porto CS. Estrogen Receptors Promote Migration, Invasion and Colony Formation of the Androgen-Independent Prostate Cancer Cells PC-3 Through $\beta$-Catenin Pathway. Front Endocrinol (Lausanne) (2020) 11:184. doi: 10.3389/fendo.2020.00184 
28. Cotrim CZ, Fabris V, Doria ML, Lindberg K, Gustafsson JÅ, Amado F, et al. Estrogen Receptor Beta Growth-Inhibitory Effects Are Repressed Through Activation of MAPK and PI3K Signalling in Mammary Epithelial and Breast Cancer Cells. Oncogene (2013) 32(19):2390-402. doi: 10.1038/onc.2012.261

29. Pisolato R, Lombardi AP, Vicente CM, Lucas TF, Lazari MF, Porto CS. Expression and Regulation of the Estrogen Receptors in PC-3 Human Prostate Cancer Cells. Steroids (2016) 107:74-86. doi: 10.1016/j.steroids.2015.12.021

30. Dey P, Jonsson P, Hartman J, Williams C, Ström A, Gustafsson JÅ. Estrogen Receptors $\beta 1$ and $\beta 2$ Have Opposing Roles in Regulating Proliferation and Bone Metastasis Genes in the Prostate Cancer Cell Line PC3. Mol Endocrinol (2012) 26(12):1991-2003. doi: 10.1210/me.2012.1227

31. Schade GR, Holt SK, Zhang X, Song D, Wright JL, Zhao S, et al. Prostate Cancer Expression Profiles of Cytoplasmic Er $\beta 1$ and Nuclear Er $\beta 2$ Are Associated With Poor Outcomes Following Radical Prostatectomy. J Urol (2016) 195(6):1760-6. doi: 10.1016/j.juro.2015.12.101

32. Lau KM, To KF. Importance of Estrogenic Signaling and Its Mediated Receptors in Prostate Cancer. Int J Mol Sci (2016) 17(9):1434. doi: 10.3390/ ijms17091434

33. Rago V, Romeo F, Giordano F, Ferraro A, Carpino A. Identification of the G Protein-Coupled Estrogen Receptor (GPER) in Human Prostate: Expression Site of the Estrogen Receptor in the Benign and Neoplastic Gland. Andrology (2016) 4(1):121-7. doi: 10.1111/andr.12131

34. Xu S, Yu S, Dong D, Lee LTO. G Protein-Coupled Estrogen Receptor: A Potential Therapeutic Target in Cancer. Front Endocrinol (Lausanne) (2019) 10:725. doi: 10.3389/fendo.2019.00725

35. Chan QK, Lam HM, Ng CF, Lee AY, Chan ES, Ng HK, et al. Activation of GPR30 Inhibits the Growth of Prostate Cancer Cells Through Sustained Activation of Erk1/ 2, C-Jun/C-Fos-Dependent Upregulation of P21, and Induction of G(2) Cell-Cycle Arrest. Cell Death Differ (2010) 17(9):1511-23. doi: 10.1038/cdd.2010.20

36. Daniels G, Gellert LL, Melamed J, Hatcher D, Li Y, Wei J, et al. Decreased Expression of Stromal Estrogen Receptor $\alpha$ and $\beta$ in Prostate Cancer. Am J Transl Res (2014) 6(2):140-6.

37. Dey P, Barros RP, Warner M, Ström A, Gustafsson JÅ. Insight Into the Mechanisms of Action of Estrogen Receptor $\beta$ in the Breast, Prostate, Colon, and CNS. J Mol Endocrinol (2013) 51(3):T61-74. doi: 10.1530/JME-13-0150

38. Dey P, Ström A, Gustafsson JÅ. Estrogen Receptor $\beta$ Upregulates FOXO3a and Causes Induction of Apoptosis Through PUMA in Prostate Cancer. Oncogene (2014) 33(33):4213-25. doi: 10.1038/onc.2013.384

39. Royer C, Lucas TF, Lazari MF, Porto CS. 17Beta-Estradiol Signaling and Regulation of Proliferation and Apoptosis of Rat Sertoli Cells. Biol Reprod (2012) 86(4):108. doi: 10.1095/biolreprod.111.096891

40. Lau KM, Ma FM, Xia JT, Chan QKY, Ng CF, To KF. Activation of GPR30 Stimulates GTP-Binding of Goil Protein to Sustain Activation of Erk1/2 in Inhibition of Prostate Cancer Cell Growth and Modulates Metastatic Properties. Exp Cell Res (2017) 350(1):199-209. doi: 10.1016/j.yexcr. 2016.11.022

41. Lam HM, Ouyang B, Chen J, Ying J, Wang J, Wu CL, et al. Targeting GPR30 With G-1: A New Therapeutic Target for Castration-Resistant Prostate Cancer. Endocr Relat Cancer (2014) 21(6):903-14. doi: 10.1530/ERC-14-0402

42. Zhang Q, Wu YZ, Zhang YM, Ji XH, Hao Q. Activation of G-Protein Coupled Estrogen Receptor Inhibits the Proliferation of Cervical Cancer Cells via Sustained Activation of ERK1/2. Cell Biochem Funct (2015) 33(3):134-42. doi: 10.1002/cbf.3097

43. Prossnitz ER, Barton M. The G-Protein-Coupled Estrogen Receptor GPER in Health and Disease. Nat Rev Endocrinol (2011) 7(12):715-26. doi: 10.1038/ nrendo.2011.122

44. Alexandrova E, Lamberti J, Saggese P, Pecoraro G, Memoli D, Cappa VM, et al. Small Non-Coding RNA Profiling Identifies miR-181a-5p as a Mediator of Estrogen Receptor Beta-Induced Inhibition of Cholesterol Biosynthesis in Triple-Negative Breast Cancer. Cells (2020) 9(4):874. doi: 10.3390/ cells 9040874
45. Omarjee S, Jacquemetton J, Poulard C, Rochel N, Dejaegere A, Chebaro Y, et al. The Molecular Mechanisms Underlying the Er $\alpha$-36-Mediated Signaling in Breast Cancer. Oncogene (2017) 36(18):2503-14. doi: 10.1038/onc.2016.415

46. Wang ZY, Yin L. Estrogen Receptor Alpha-36 (ER- 236$)$ : A New Player in Human Breast Cancer. Mol Cell Endocrinol (2015) 418 Pt 3:193-206. doi: 10.1016/j.mce.2015.04.017

47. Fujimura T, Takayama K, Takahashi S, Inoue S. Estrogen and Androgen Blockade for Advanced Prostate Cancer in the Era of Precision Medicine. Cancers (Basel) (2018) 10(2):29. doi: 10.3390/cancers10020029

48. Dey P, Velazquez-Villegas LA, Faria M, Turner A, Jonsson P, Webb P, et al. Estrogen Receptor $\beta 2$ Induces Hypoxia Signature of Gene Expression by Stabilizing HIF-1 $\alpha$ in Prostate Cancer. PloS One (2015) 10(5):e0128239. doi: 10.1371/journal.pone. 0128239

49. Lin X, Roy S, Jolly MK, Bocci F, Schafer NP, Tsai MY, et al. PAGE4 and Conformational Switching: Insights From Molecular Dynamics Simulations and Implications for Prostate Cancer. J Mol Biol (2018) 430(16):2422-38. doi: 10.1016/j.jmb.2018.05.011

50. Vihko P, Härkönen P, Soronen P, Törn S, Herrala A, Kurkela R, et al. 17 BetaHydroxysteroid Dehydrogenases-Their Role in Pathophysiology. Mol Cell Endocrinol (2004) 215(1-2):83-8. doi: 10.1016/j.mce.2003.11.021

51. Carruba G. Estrogen and Prostate Cancer: An Eclipsed Truth in an AndrogenDominated Scenario. J Cell Biochem (2007) 102(4):899-911. doi: 10.1002/ jcb. 21529

52. Jurečeková J, Sivoňová MK, Drobková $\mathrm{H}$, Híveš $\mathrm{M}$, Evin $\mathrm{D}$, Kliment J, et al. Association Between Estrogen Receptor $\beta$ Polymorphisms and Prostate Cancer in a Slovak Population. Oncol Lett (2021) 21(3):214. doi: 10.3892/ ol.2021.12475

53. Teo MY, Rathkopf DE, Kantoff P. Treatment of Advanced Prostate Cancer. Annu Rev Med (2019) 70:479-99. doi: 10.1146/annurev-med-051517-011947

54. Hoyle AP, Ali A, James ND, Cook A, Parker CC, de Bono JS, et al. Abiraterone in "High-" and "Low-Risk" Metastatic Hormone-Sensitive Prostate Cancer. Eur Urol (2019) 76(6):719-28. doi: 10.1016/j.eururo.2019.08.006

55. de Bono JS, Logothetis CJ, Molina A, Fizazi K, North S, Chu L, et al. Abiraterone and Increased Survival in Metastatic Prostate Cancer. N Engl J Med (2011) 364(21):1995-2005. doi: 10.1056/NEJMoa1014618

56. Vivacqua A, Romeo E, De Marco P, De Francesco EM, Abonante S, Maggiolini M. GPER Mediates the Egr-1 Expression Induced by $17 \beta$ Estradiol and 4-Hydroxitamoxifen in Breast and Endometrial Cancer Cells. Breast Cancer Res Treat (2012) 133(3):1025-35. doi: 10.1007/s10549-0111901-8

57. Paterni I, Granchi C, Katzenellenbogen JA, Minutolo F. Estrogen Receptors Alpha $(\operatorname{Er} \alpha)$ and Beta $(\operatorname{Er} \beta)$ : Subtype-Selective Ligands and Clinical Potential. Steroids (2014) 90:13-29. doi: 10.1016/j.steroids.2014.06.012

Conflict of Interest: The authors declare that the research was conducted in the absence of any commercial or financial relationships that could be construed as a potential conflict of interest.

Publisher's Note: All claims expressed in this article are solely those of the authors and do not necessarily represent those of their affiliated organizations, or those of the publisher, the editors and the reviewers. Any product that may be evaluated in this article, or claim that may be made by its manufacturer, is not guaranteed or endorsed by the publisher.

Copyright (๑) 2022 Ramírez-de-Arellano, Pereira-Suárez, Rico-Fuentes, López-Pulido, Villegas-Pineda and Sierra-Diaz. This is an open-access article distributed under the terms of the Creative Commons Attribution License (CC BY). The use, distribution or reproduction in other forums is permitted, provided the original author(s) and the copyright owner(s) are credited and that the original publication in this journal is cited, in accordance with accepted academic practice. No use, distribution or reproduction is permitted which does not comply with these terms. 